\title{
Soil for Resource Management and Sustainability
}

\author{
Raj $\mathrm{A}^{1 *}$ and Jhariya $\mathrm{MK}^{2}$ \\ ${ }^{1}$ Department of Forestry, Mewar University, India \\ ${ }^{2}$ Department of Farm Forestry, Sant Gahira Guru Vishwavidyalaya, Sarguja, India
}

*Corresponding author: Abhishek Raj, Department of Forestry, Mewar University, Chittaurgarh-312901 (Rajasthan), India, Tel: 8269718066; Email: ranger0392@gmail.com

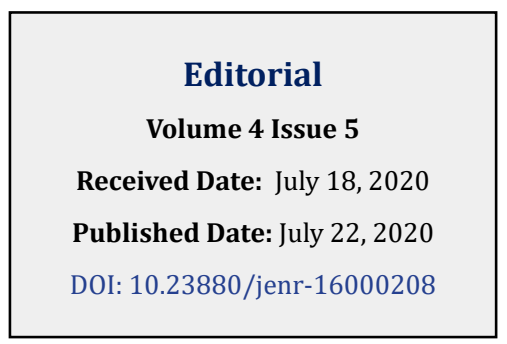

\section{Editorial}

Soil, also known as "Soul of Infinite Life", sustain diversified flora and fauna and maintains ecosystem structure and services. Soil supports other natural resources such as forest, agriculture, animals and humans etc and moreover there is a great relationship exists among them. Resource conservation is basic pillar that ensure for achieving the goal of sustainability. Soil is a largest natural resource that harbors microbial populations and maintains rhizosphere biology. Soil decides vegetation types and their structure, compositions and diversity. One question arises in my mind "How soil manage other natural resources?" There is a two school of thoughts. First, decomposition and decaying of litter and plant residues release carbon and other essential nutrients into the soils that maintain soil fertility, productivity and rhizosphere biology. Secondly, these carbon improve the SOC pools and nutrient resources are consumed and uptake by extensive root system of higher plant that improve plant growth and development along with higher productivity. Thus, we can say there is a great nexus exists between soil health and plant productivity.

Burgeoning populations leads to deforestation and other anthropogenic activities such as illicit felling of trees, unsustainable land use practices, intensive agricultural system, mining, several development projects, industrial development etc that deprived the soil health and quality. These deleterious activities not only affect soil but also destroy other natural resources along with GHGs emissions into the atmosphere. Therefore, continuous and unstoppable emissions of green house gases cause global warming and climate change phenomenon. In this context, a practice of sustainable soil management becomes a good strategy that does not only minimize climate change but also maintains environmental sustainability and ecological stability at global scale. That's why, one question triggered my soul "How sustainable soil management (SSM) promise resource conservations and ecosystem services?" Thus, the practices of SSM ensure a better soil fertility, healthy microbial populations \& rhizosphere biology, higher nutrient use efficiency; efficient nutrient cycling that leads to healthy environment and ecosystem. SSM based practices enhance biodiversity that intensify ecosystem services that maintains food and nutritional security. Health soil maintains human health \& wealth by providing multifarious and uncountable nutritious food and fruits. Soil nutrients are foremost and essentials for a better growth and development of plants that in turn produce quality fruits which is consume by humans and animals that maintains food and climate security. However, natural resource management is a very essential for soil-food-climate security along with maintaining environmental sustainability and ecological stability.

Moreover, the practices of sustainable soil management conserve natural resources and enhance soil carbon sequestration in which soil absorbs atmospheric carbon and fix it in the forms of organic carbon as SOC pools. These pools maintain carbon status into the soil and make carbon balance in the environment to mitigate climate change phenomenon. Climate change is burning topic today and most talkative words by policy makers, stakeholders, researchers, scientists, and acamedecians at both national and international platforms. But the practices of SSM are not only enhancing the potential of soil carbon sequestration but also maintain carbon balance into the atmosphere. Thus, our future is totally depends on soil. So, a better management of soils would be helpful in conserving other resources along with maintaining sustainability and ecological stability. A good governance and policy are needed to avoid the faulty land use practices, forest cutting, overexploitation of resources, high synthetic inputs, intensive agricultural practices etc that are major hurdle behind success of SSM and resource conservations. The term "sustainability" is achieved through SSM by maintain resources for present and future generations without disturbing our environment. In nutshell, 
sustainable soil management is a better tool to achieve the goal of sustainability along with effective management and conservation of other resources that regulates ecosystem processes and maintains soil-food-climate security along with ecological and environmental stability (Figure 1) [1,2].

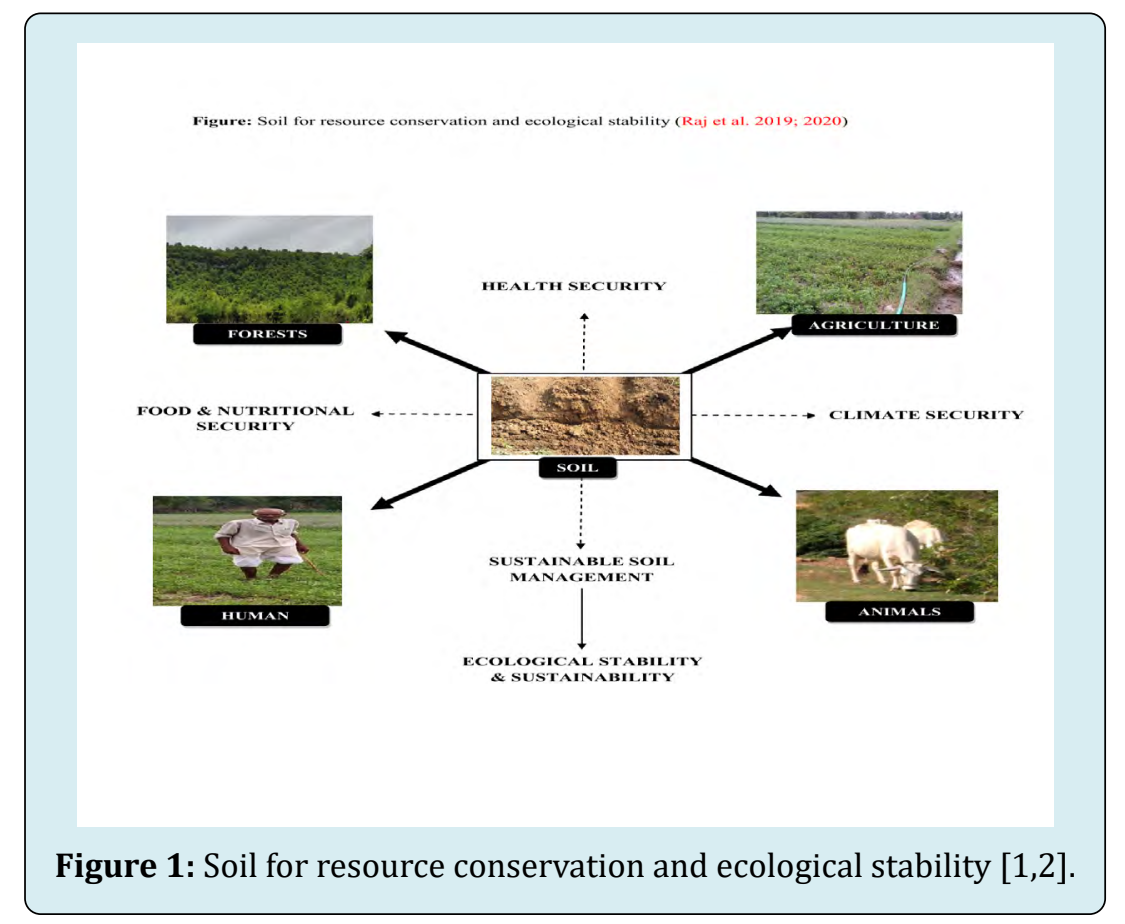

\section{References}

1. Raj A, Jhariya MK, Yadav DK, Banerjee A, Meena RS (2019) Soil for Sustainable Environment and Ecosystems Management. Sustainable Agriculture, Forest and
Environmental Management pp: 189-221.

2. Raj A, Jhariya MK, Yadav DK, Banerjee A, Oraon PR (2020) Climate Change, Soil Health, and Food Security: A Critical Nexus. Climate Change and Agroforestry System: 143-168.

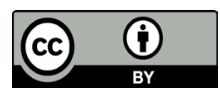

